\title{
Aeromonas salmonicida
}

National Cancer Institute

\section{Source}

National Cancer Institute. Aeromonas salmonicida. NCI Thesaurus. Code C86128.

A species of facultatively anaerobic, Gram negative, rod shaped bacteria assigned to the phylum Proteobacteria. This bacteria is non motile, capable of both aerobic and anaerobic respiration, ferments glucose and is generally oxidase positive. A. solmonicida is found in freshwater and marine environments and causes furunculosis in fish and bald sea urchin disease. 